\title{
DETERMINAN KEMATIAN IBU DI PROPINSI JAWA TIMUR PADA MASA PANDEMI COVID 19
}

\author{
Eka Diah Kartiningrum ${ }^{1}$, Hari Basuki Notobroto ${ }^{2}$ \\ ${ }^{1}$ Dosen S2 Kesehatan Masyarakat Stikes Majapahit Mojokerto \\ ${ }^{2}$ Dosen Prodi S3 Kesehatan Masyarakat Universitas Airlangga Surabaya
}

\begin{abstract}
The Covid 19 pandemic affected all aspects of life and almost all groups of society, including pregnant, childbirth and postpartum woman. This study aimed to analyze the effect of spatial determinants that consist of antenatal care, childbirth services, post-partum services and demographic factors on maternal mortality in East Java Province before and during the Pandemic Era. This study was an unobstrusive measure research with the unit of analysis in this study were all pregnant, childbirth and postpartum women that spread accros 38 districts in East Java Province during 2020. Data were analyzed using Geographically Weighted Regression.The results showed that maternal mortality in the province of East Java had a spreading pattern, thus indicating a spatial influence. The variables of childbirth services by health personnel and antenatal care had a significant effect on maternal mortality. There are 5 groups of districts that show a similarity of significant factors. This result showed that the diversity of health service accessibility in each region affects maternal mortality during the Covid 19 pandemic in East Java province. Childbirth assistance by health personnel and accessibility of antenatal services during the Covid 19 Pandemic affected maternal mortality.The diversity of accessibility influenced by local government policies and community perceptions in each region about Covid 19 pandemic will affect the accessibility of antenatal services and childbirth so it can be dangerous for the safety of pregnant, childbirth and postpartum woman.
\end{abstract}

Keyword: maternal, mortality, determinant

\section{A. PENDAHULUAN}

Setiap hari, sekitar 830 wanita meninggal karena penyebab yang dapat dicegah terkait dengan kehamilan dan persalinan. Sembilan puluh sembilan persen dari semua kematian ibu terjadi di negara berkembang. Sekitar 830 wanita meninggal akibat komplikasi kehamilan atau persalinan di seluruh dunia setiap hari. Salah satu target SDGs adalah menurunkan rasio kematian ibu global hingga kurang dari 70 per 100.000 kelahiran hidup, dengan tidak ada negara yang memiliki angka kematian ibu lebih dari dua kali rata-rata global untuk jumlah wanita yang meninggal akibat komplikasi selama dan setelah kehamilan dan persalinan. Komplikasi utama yang menyebabkan hampir 75\% dari seluruh kematian ibu adalah perdarahan postpartum berat, infeksi, tekanan darah tinggi selama kehamilan (pre-eklampsia dan eklampsia), komplikasi persalinan, dan aborsi yang tidak aman.

Angka kematian ibu di Indonesia adalah 305 per 100.000 kelahiran hidup pada tahun 2015. Angka ini 9 kali lebih tinggi dari Malaysia, 5 kali lebih tinggi dari Vietnam dan hampir 2 kali dari Kamboja. Persentase wanita yang tidak mengalami komplikasi selama kehamilan menurun dari 89 persen dalam Survei Demografi dan Kesehatan Indonesia menjadi 81 persen pada tahun 2017. Pendarahan berlebihan masih merupakan 
gejala komplikasi kehamilan yang paling banyak dilaporkan, dengan persentase sedikit meningkat dari 3 persen ( 2007) menjadi 5 persen pada tahun 2017. Salah satu ciri pola dan latar belakang terjadinya komplikasi pada kehamilan adalah sepuluh persen ibu mengalami perdarahan yang berlebihan, bayinya meninggal pada usia 1 bulan dan 8 persen ibu melahirkan melalui operasi caesar.

Perhimpunan Obstetri dan Ginekologi Indonesia (2020) mengatakan peningkatan risiko infeksi harus dicegah selama pandemi Covid-19. Ibu nifas memiliki peningkatan risiko infeksi pasca persalinan dengan luka perineum yang kurang terawat, dimana titik masuk mikroorganisme penyebab infeksi dan jaringan nekrosis di sekitar luka perineum merupakan media yang paling subur untuk berkembangnya mikroorganisme. Perilaku yang dianjurkan bagi ibu nifas adalah mencuci tangan, menjaga jarak dan memakai masker dengan menjaga kebersihan diri dan bayi.

Hasil penelitian Corbett et al (2020) menemukan bahwa 83,1\% wanita mengalami kekhawatiran tentang kesehatannya sejak pandemi COVID-19, sedangkan ibu hamil mengalami peningkatan kekhawatiran lebih dari 50,7\%. Kekhawatiran ini termasuk kekhawatiran tentang $66,7 \%$ kehamilan dan $35 \%$ perawatan bayi2. Penelitian lain mengatakan bahwa sebagian besar ibu hamil mengkhawatirkan kesehatannya dan janin yang dikandungnya sepanjang waktu3. Secara umum, perubahan fisiologis dan mekanis pada kehamilan meningkatkan kerentanan terhadap infeksi, terutama ketika sistem kardiorespirasi terpengaruh, dan mendorong perkembangan yang cepat menjadi gagal napas pada wanita hamil. Adanya perubahan psikologis tersebut dapat mempengaruhi ibu hamil selama perawatan sampai dengan masa nifas4.

Kematian ibu dipengaruhi oleh 3 faktor utama menurut McCarty \& Maine antara lain determinan dekat (komplikasi kehamilan, komplikasi persalinan dan nifas), determinan menengah (status kesehatan ibu yang terdiri dari anemia, status gizi, penyakit yang diderita ibu, riwayat komplikasi sebelumnya). kehamilan dan persalinan Status reproduksi yang terdiri dari umur ibu hamil, jumlah kelahiran, jarak antar kehamilan, dan status perkawinan ibu; Akses terhadap pelayanan kesehatan; Perilaku menggunakan fasilitas pelayanan kesehatan yang terdiri dari perilaku KB, pemeriksaan kehamilan (perilaku K1, K4, Fe1, Fe3 dan TT1 sampai TT5, penolong persalinan dan tempat bersalin), sedangkan determinan jauh meliputi sosial budaya, ekonomi, agama, tingkat pendidikan ibu dan pengetahuan ibu tentang tanda bahaya kehamilan5,13.

Masa Pandemi Covid 19 yang terjadi pada akhir tahun 2019 di dunia dan baru terjadi di Indonesia pada bulan Maret 2020 berdampak sangat besar terhadap derajat kesehatan masyarakat khususnya kelompok ibu dan anak. Kebijakan penanganan Covid 19 seperti Pembatasan Sosial Berskala Besar, Adaptasi Kebiasaan Baru, hingga keputusan lockdown berdampak pada aksesibilitas terhadap layanan kesehatan, terutama bagi ibu dan anak. Kebijakan ini menambah tingginya angka kematian ibu yang sebenarnya masih sangat besar di tahun 2019. Setiap daerah di Indonesia memiliki kebijakan masing-masing yang terkait dengan budaya dan kebiasaan masyarakat. Oleh karena itu, peneliti ingin menganalisis pengaruh determinan spasial terhadap kematian ibu pada masa pandemi Covid 19 di Provinsi Jawa Timur.

\section{B. TINJAUAN PUSTAKA}

\section{Angka Kematian Ibu}

Angka kematian ibu (AKI) adalah banyaknya wanita yang meninggal dari 
suatu penyebab kematian terkait dengan gangguan kehamilan atau penanganannya (tidak termasuk kecelakaan atau kasus insidentil) selama kehamilan, melahirkan dan dalam masa nifas (42 hari setelah melahirkan) tanpa memperhitungkan lama kehamilan per 100.000 kelahiran hidup. AKI diperhitungkan pula pada jangka waktu 6 minggu hingga setahun setelah melahirkan. Kematian Ibu adalah kematian yang terjadi pada ibu karena peristiwa kehamilan, persalinan, dan masa nifas (Ali, 2009).

\section{Faktor Yang Mempengaruhi Angka Kematian Ibu}

Faktor - faktor risiko yang mempengaruhi kematian maternal, yang dikelompokkan berdasarkan kerangka dari McCarthy dan Maine (1992) dalam Arulita (2007) adalah sebagai berikut :

\section{a. Determinan dekat}

Proses yang paling dekat terhadap kejadian kematian maternal adalah kehamilan itu sendiri dan komplikasi dalam kehamilan, persalinan dan masa nifas. Wanita yang hamil memiliki risiko untuk mengalami komplikasi, baik komplikasi kehamilan maupun persalinan, sedangkan wanita yang tidak hamil tidak memiliki risiko tersebut.

\section{1) Komplikasi kehamilan}

Komplikasi kehamilan merupakan penyebab langsung kematian maternal.Ibu hamil resiko tinggi atau ibu hamil dengan komplikasi kehamilan adalah ibu hamil dengan keadaan penyimpangan dari normal yang secara langsung dapat menyebabkan kesakitan dan kematian bagi ibu maupun bayinya (Dinkes Propinsi Jawa Timur, 2010). Komplikasi kehamilan yang dapat terjadi antara lain : Perdarahan pada trimester pertama, kehamilan ektopik, mola hidatidosa, hiperemesis gravidarum, inkompetensia os serviks interna, infeksi, tuberkulosis, hepatitis, rubela, sitomegalovirus, toksoplasmosis, varisela, eritema infeksiosum, infeksi saluran kemih, anemia dan hemoglobinopati, penyakit jantung, gangguan tiroid, asma, kehamilan kembar, hidramnion, diabetes mellitus, isoimmunisasi $\mathrm{Rh}(\mathrm{D})$, plasenta previa, abrupsio plasenta, gangguan hipertensi pada kehamilan (Varney, Kriebs, Gegor, 2002).

\section{2) Komplikasi persalinan dan nifas}

Komplikasi yang timbul pada persalinan dan masa nifas merupakan penyebab langsung kematian maternal. Komplikasi yang terjadi menjelang persalinan, saat dan setelah persalinan terutama adalah perdarahan, partus macet atau partus lama dan infeksi akibat trauma pada persalinan (Arulita, 2007). Menurut Varney, Kriebs, dan Gegor (2002), komplikasi yang terjadi pada masa nifas antara lain infeksi puerperium, mastitis, tromboplebitis dan emboli paru, hematoma, hemoragi pascapartum hebat, sub involusi dan depresi pasca partum.

Selama masa nifas pelayanan kesehatan yang diterima ibu nifas antara lain pemeriksaan kondisi umum (tekanan darah, nadi, respirasi dan suhu), pemeriksaan lokhia, dan pengeluaran per vaginam lainnya, pemeriksaan payudara, dan anjuran ASI eksklusif 6 bulan, pemberian kapsul vitamin A 200.000 IU sebanyak 2 kali ( 2 x 24 jam) dan 
pelayanan KB pasca persalinan. Perawatan ibu nifas yang tepat akan memperkecil resiko kelainan atau bahkan kematian pada ibu nifas. Cakupan pelayanan nifas merupakan salah satu indikator kesehatan. Cakupan pelayanan nifas yang meningkat menunjukkan bahwa petugas kesehatan semakin proaktif dalam melakukan pelayanan pada ibu nifas dalam rangka memperkecil resiko kelainan bahkan kematian pada ibu nifas (Dinkes Propinsi Jawa Timur, 2010).

\section{b. Determinan antara}

\section{1) Status kesehatan ibu}

Status kesehatan ibu yang berpengaruh terhadap kejadian kematian maternal meliputi status gizi, anemia, penyakit yang diderita ibu, dan riwayat komplikasi pada kehamilan dan persalinan sebelumnya.

\section{2) Status reproduksi}

Status reproduksi yang berperan penting terhadap kejadian kematian maternal adalah usia ibu hamil, jumlah kelahiran, jarak kehamilan dan status perkawinan ibu.

\section{3) Akses terhadap pelayanan kesehatan}

Hal ini meliputi antara lain keterjangkauan lokasi tempat pelayanan kesehatan, dimana tempat pelayanan yang lokasinya tidak strategis / sulit dicapai oleh para ibu menyebabkan berkurangnya akses ibu hamil terhadap pelayanan kesehatan, jenis dan kualitas pelayanan yang tersedia dan keterjangkauan terhadap informasi. Akses terhadap tempat pelayanan kesehatan dapat dilihat dari beberapa faktor, seperti lokasi dimana ibu dapat memperoleh pelayanan kontrasepsi, pemeriksaan antenatal, pelayanan kesehatan primer atau pelayanan kesehatan rujukan yang tersedia di masyarakat

\section{4) Perilaku penggunaan fasilitas pelayanan kesehatan}

Perilaku penggunaan fasilitas pelayanan kesehatan antara lain meliputi perilaku penggunaan alat kontrasepsi, dimana ibu yang mengikuti program keluarga berencana (KB) akan lebih jarang melahirkan dibandingkan dengan ibu yang tidak ber $\mathrm{KB}$, perilaku pemeriksaan antenatal, dimana ibu yang melakukan pemeriksaan antenatal secara teratur akan terdeteksi masalah kesehatan dan komplikasinya, penolong persalinan, dimana ibu yang ditolong oleh dukun berisiko lebih besar untuk mengalami kematian dibandingkan dengan ibu yang melahirkan dibantu oleh tenaga kesehatan, serta tempat persalinan, dimana persalinan yang dilakukan di rumah akan menghambat akses untuk mendapatkan pelayanan rujukan secara cepat apabila sewaktu - waktu dibutuhkan (Arulita, 2007).

\section{a) Pelayanan Antenatal}

Pelayanan antenatal merupakan pelayanan kesehatan oleh tenaga kesehatan profesional (dokter spesialis kandungan dan kebidanan, dokter umum, bidan dan perawat) seperti mengukur berat badan dan tekanan darah, pemeriksaan tinggi fundus uteri, 
imunisasi tetanus toxoid (TT) serta pemberian tablet besi pada ibu hamil selama masa kehamilannya sesuai dengan pedoman pelayanan antenatal yang ada dengan titik berat pada kegiatan promotif dan preventif. Hasil pelayanan antenatal dapat dilihat dari cakupan pelayanan K1 dan K4. Cakupan K1 atau disebut juga akses pelayanan kesehatan ibu hamil merupakan gambaran besaran ibu hamil yang telah melakukan kunjungan pertama ke sarana kesehatan untuk mendapatkan pelayanan antenatal. Sedangkan cakupan K4 adalah gambaran besaran ibu hamil yang mendapatkan pelayanan ibu hamil sesuai standar serta paling sedikit 4 kali kunjungan dengan distribusi sekali pada trimester pertama, sekali pada trimester kedua dan dua kali pada trimester ke tiga. Rendahnya cakupan K4 menunjukkan bahwa masih banyak ibu hamil yang tidak meneruskan hingga kunjungan ke 4 pada triwulan ke 3 sehingga kehamilannya lepas dari pemantauan petugas kesehatan.

Kondisi tersebut membuka peluang terjadinya kematian pada ibu melahirkan dan bayi yang dikandungnya (Dinas Kesehatan Propinsi Jawa Timur, 2010). Indikator kunjungan antenatal care (ANC) terdiri dari 4 macam diantaranya: cakupan kunjungan baru (K1), cakupan kunjungan ke 4 atau lebih (K4), cakupan imunisasi TT, dan cakupan pemberian tablet Fe. Salah satu standar minimal pelayanan antenatal adalah pemberian imunisasi TT. Tujuan pemberian imunisasi TT adalah untuk memberikan perlindungan pasif pada ibu hamil terhadap tetanus, vaksinasi ini juga membantu menghindari tetanus selama beberapa minggu pada bayinya yang baru lahir (Fauziah, Sutejo, 2012).

Bagi wanita hamil yang telah terpajan tetanus maka diberikan globulin hiperimun dengan vaksin (toksoid) pada wanita yang tidak divaksinasi (Reeder, Martin, Koniak-Griffin, 2003).Intruksi terbaru dari departemen kesehatan dalam Fauziah dan Sutejo (2012) adalah diberikan sebanyak 5 kali.Jika CPW (Calon Pengantin Wanita) sudah mendapatkan lengkap 5 kali maka selama hamil tidak perlu diberikan suntikan TT lagi.

Kematian ibu hamil masih tinggi di Indonesia yang sebetulnya dapat dicegah dengan cara melakukan pemeliharaan dan perawatan antenatal sedini mungkin. Perawatan antenatal (antenatal care) adalah perawatan yang diberikan kepada ibu selama kehamilannya dengan maksud agar kehamilannya berakhir dengan kelahiran bayi yang sehat fisik maupun mental serta ibu dalam keadaan selamat, sehat serta dapat merawat dan meneteki bayi yang dilahirkannya. Dalam pelayanan ANC dilakukan pemeriksaan dan pengawasan ibu selama kehamilannya secara berkala dan teratur sehingga apabila timbul kelainan kehamilannya dapat dikenal sedini mungkin sehingga dapat dilakukan perawatan yang cepat dan tepat. Tujuan perawatan antenatal adalah sebagai berikut: untuk mengurangi penyulit-penyulit pada masa sebelum melahirkan, untuk mempertahankan kesehatan jasmaniah dan 
rohaniah ibu, supaya persalinan dapat berlangsung dengan aman, supaya ibu sesehat-sehatnya sesudah melahirkan dan supaya ibu dapat memenuhi kebutuhan janinnya (Suparman, 2007).

Risiko kematian ibu dapat diperparah oleh adanya anemia dan penyakit menular seperti malaria, Tuberkulosis (TB), hepatitis, dan HIV/AIDS. Pada 1995, misalnya, prevalensi anemia pada ibu hamil masih sangat tinggi, yaitu 51 persen, dan pada ibu nifas 45 persen. Anemia pada ibu hamil mempunyai dampak kesehatan terhadap ibu dan anak dalam kandungan, meningkatkan risiko keguguran, kelahiran prematur, bayi dengan berat lahir rendah, serta sering menyebabkan kematian ibu dan bayi baru lahir. Anemia atau kurang darah merupakan salah satu penyebab utama kematian ibu. Ibu hamil yang anemia tidak dapat memenuhi kebutuhan tubuh ibu dan janin akan nutrisi dan oksigen yang dibawa dalam darah, sehingga pertumbuhan janin terganggu. Wanita yang mengidap anemia saat melahirkan dapat mengalami syok karena kehilangan banyak darah dan dapat mengakibatkan kematian (Leger, P., dan Chansel, J., 2006).

Penanganan defisiensi zat besi melalui progam $\mathrm{Fe} 1$ dan $\mathrm{Fe} 3$ dalam ANC dengan pemberian suplemen tablet besi, efektif untuk meningkatkan kadar Fe/besi dalam jangka waktu pendek sehingga dapat mencegah terjadinya anemia (Dinkes Kab. Cirebon, 2006). Zat besi sangat dibutuhkan untuk mengurangi angka kematian ibu dan anak. Di Indonesia 2700 kematian ibu disebabkan oleh anemia berat dengan penyebab utama adalah kekurangan zat besi. Untuk mencegah kekurangan zat besi pada ibu dan bayi baru lahir, seorang wanita harus mengkomsumsi tablet zat besi sebelum hamil, selama dan sesudah melahirkan. Dengan menganjurkan dosis 1 tablet (60 $\mathrm{mg}$ zat besi $+0,25 \mathrm{mg}$ asam folat) setiap hari (Leger, P., dan Chansel, J., 2006).

\section{b) Pertolongan Persalinan Oleh Tenaga Kesehatan (linakes)}

Salah satu indikator kematian maternal yang lain adalah persalinan oleh tenaga kesehatan. Pertolongan persalinan oleh tenaga kesehatan adalah pertolongan persalinan oleh tenaga ahli yang profesional (dengan kompetensi kebidanan) dimulai dari lahirnya bayi, pemotongan tali pusat sampai keluarnya plasenta. Komplikasi dan kematian maternal serta bayi baru lahir sebagian besar terjadi dimasa persalinan. Hal ini disebabkan persalinan yang tidak dilakukan oleh tenaga kesehatan yang memiliki kompetensi kebidanan (profesional) (Dinas Kesehatan Propinsi Jawa Timur, 2010). Tenaga penolong persalinan yang tidak profesional akan menyebabkan timbulnya bahaya pada ibu bersalin yang pada akhirnya berdampak pada terjadinya kematian pada ibu nifas akibat kurang tepat dalam pengendalian perdarahan yang terjadi pada masa nifas. 


\section{c. Determinan jauh}

Meskipun determinan ini tidak secara langsung mempengaruhi kematian maternal, akan tetapi faktor sosio kultural, ekonomi, keagamaan dan faktor - faktor lain juga perlu dipertimbangkan dan disatukan dalam pelaksanaan intervensi penanganan kematian maternal. Termasuk dalam determinan jauh adalah status wanita dalam keluarga dan masyarakat, yang meliputi tingkat pendidikan, dimana wanita yang berpendidikan tinggi cenderung lebih memperhatikan kesehatan diri dan keluarganya, sedangkan wanita dengan tingkat pendidikan yang rendah, menyebabkan kurangnya pengertian mereka akan bahaya yang dapat menimpa ibu hamil maupun bayinya terutama dalam hal kegawatdaruratan kehamilan dan persalinan. Ibu - ibu terutama di daerah pedesaan atau daerah terpencil dengan pendidikan rendah, tingkat independensinya untuk mengambil keputusanpun rendah. Pengambilan keputusan masih berdasarkan pada budaya 'berunding' yang berakibat pada keterlambatan merujuk. Rendahnya pengetahuan ibu dan keluarga tentang tanda - tanda bahaya pada kehamilan mendasari pemanfaatan sistem rujukan yang masih kurang. Juga ditemukan bahwa faktor yang berpengaruh paling penting dalam perilaku mencari pelayanan kesehatan antenatal adalah pendidikan. Lebih dari 90\% wanita yang berpendidikan minimal sekolah dasar telah mencari pelayanan kesehatan antenatal. Pekerjaan ibu, dimana keadaan hamil tidak berarti mengubah pola aktivitas bekerja ibu hamil sehari - hari. Hal tersebut terkait dengan keadaan ekonomi keluarga, pengetahuan ibu sendiri yang kurang, atau faktor kebiasaan setempat. Kemiskinan dapat menjadi sebab rendahnya peran serta masyarakat pada upaya kesehatan. Kematian maternal sering terjadi pada kelompok miskin, tidak berpendidikan, tinggal di tempat terpencil, dan mereka tidak memiliki kemampuan untuk memperjuangkan kehidupannya sendiri.

\section{METODE PENELITIAN}

Penelitian ini merupakan penelitian non reaktif atau tidak mengganggu karena pengukuran variabel penelitian yang akan digunakan peneliti menggunakan data sekunder. Pengukuran tidak mengganggu menekankan bagaimana individu yang diteliti tidak menyadari penelitian karena pengukuran tidak mengganggu individu dan individu tidak merasa terganggu19,20. Data yang digunakan dalam penelitian ini adalah data sekunder profil Dinas Kesehatan Provinsi Jawa Timur Tahun 2020-2021. Data yang dianalisis meliputi pelayanan kehamilan yaitu cakupan pelayanan antenatal (kunjungan trimester $1 / \mathrm{K} 1$ dan kunjungan trimester akhir/K4, aksesibilitas tablet $\mathrm{Fe}$, cakupan imunisasi TT untuk ibu hamil), pelayanan persalinan (pertolongan persalinan oleh tenaga kesehatan, dan ketersediaan fasilitas kesehatan). fasilitas), dan perawatan nifas (kunjungan nifas terakhir, cakupan penerimaan kapsul vitamin A dan penanganan komplikasi nifas).

Unit analisis data adalah data ibu hamil dan nifas di 38 kabupaten/kota di Provinsi Jawa Timur. Langkah awal dalam penelitian ini dimulai dengan menguji sebaran data menggunakan uji sampel Kolmogorov Smirnov 1. Pengujian dilakukan untuk membuktikan bahwa bentuk distribusi variabel angka kematian ibu (Y) mengikuti distribusi normal sebagai syarat regresi untuk mengetahui pengaruh masing-masing 
indikator terhadap kematian ibu. Jika angka kematian ibu tidak mengikuti distribusi normal, maka dapat dilakukan boostrapping dan dilanjutkan dengan analisis regresi lain yang memenuhi syarat distribusi tertentu, seperti regresi linier jika data tidak berdistribusi normal, tidak multikolinier, memenuhi asumsi linieritas. , dan memenuhi asumsi homoskedastisitas. Jika data berdistribusi normal, maka dilanjutkan dengan analisis regresi spasial sehingga diperoleh parameter yang paling signifikan dan ditemukan model yang paling sesuai dengan data.

Hasil pengujian parameter parsial dapat digunakan untuk membangun sebuah model. Langkah selanjutnya adalah menguji model terbaik menggunakan AIC. Model dengan AIC terkecil dipilih sebagai model terbaik dalam menjelaskan faktor-faktor yang mempengaruhi kematian ibu di Provinsi Jawa Timur sebelum dan sesudah pandemi Covid 19.

\section{HASIL PENELITIAN}

Hasil uji normalitas determinan spasial kematian ibu dengan menggunakan Kolmogorov Smirnov Test menunjukkan bahwa kematian ibu (AKI), ANC I, ANC terakhir, penolong tenaga kesehatan, aksesibilitas fasilitas pelayanan kesehatan, kunjungan nifas III, aksesibilitas Vitamin A, imunisasi TT, aksesibilitas tablet besi (Fe) dan pelayanan komplikasi berdistribusi normal.

Uji kolinieritas menggunakan Varian Inflation Factor (VIF) menunjukkan kematian ibu (AKI), K1, K4, Persalinan oleh tenaga kesehatan (linakes), aksesibilitas fasilitas pelayanan kesehatan, kunjungan nifas ke 3, aksesibilitas Vitamin A, imunisasi TT, aksesibilitas zat besi (Fe) dan pelayanan komplikasi memiliki VIF dibawah 10 sehingga dapat disimpulkan bahwa semua determinan spasial kematian ibu tidak memiliki multikolinieritas. Jadi semua variabel determinan memenuhi syarat untuk regresi spasial.

\section{Tabel 1 Hasil Analisis Deskriptif Pada Determinan Kematian Ibu}

\begin{tabular}{|c|c|c|c|c|}
\hline No. & Variabel & Maksimum & Minimum & $\begin{array}{c}\text { Standar } \\
\text { Deviasi }\end{array}$ \\
\hline 1 & K1 & 105,9 & 86,6 & 4,05 \\
\hline 2 & K4 & 99,3 & 78,5 & 5,06 \\
\hline 3 & Linakes & 105,2 & 84,5 & 4,38 \\
\hline 4 & $\begin{array}{c}\text { Akses ke pelayanan } \\
\text { kesehatan }\end{array}$ & 105,1 & 59,6 & 7,35 \\
\hline 5 & KF3 & 105,7 & 83,0 & 4,71 \\
\hline 6 & Vit A & 104,1 & 55,9 & 9,33 \\
\hline 7 & TT & 471,4 & 11,5 & 75,86 \\
\hline 8 & Fe & 99,3 & 40,2 & 10,08 \\
\hline 9 & Pelayanan komplikasi & 135,1 & 74,2 & 15,89 \\
\hline
\end{tabular}


Pada masa pandemi Covid-19, jumlah kematian di Provinsi Jawa Timur mencapai 585 kematian dengan jumlah tertinggi terjadi di Jember dan terendah terjadi di Madiun.

Tabel 2 Hasil Analisis Faktor Determinan Kematian Ibu Menggunakan GWR

\begin{tabular}{|c|c|c|c|c|}
\hline No. & Variable & Estimate & SE & $\mathbf{Z}$ \\
\hline 1 & K1 & $-0,066$ & 0,024 & $-2,639$ \\
\hline 2 & K4 & $-0,031$ & 0,013 & $-2,301$ \\
\hline 3 & Linakes & 0,021 & 0,028 & 0,748 \\
\hline 4 & $\begin{array}{c}\text { Akses ke pelayanan } \\
\text { kesehatan }\end{array}$ & $-0,015$ & 0,008 & $-1,958$ \\
\hline 5 & KF3 & 0,069 & 0,029 & 2,397 \\
\hline 6 & Vit A & $-0,014$ & 0,008 & $-1,931$ \\
\hline 7 & TT & 0,001 & 0,008 & 0,0632 \\
\hline 8 & Fe & 0,003 & 0,007 & 0,493 \\
\hline 9 & Pelayanan komplikasi & 0,007 & 0,003 & 2,357 \\
\hline
\end{tabular}

Setiap wilayah memiliki determinan spasial yang berbeda-beda. Terdapat 5 kelompok kecamatan yang menunjukkan kesamaan faktor signifikan. Variabel pelayanan persalinan oleh tenaga kesehatan, ANC pertama dan terakhir berpengaruh signifikan terhadap kematian ibu di setiap wilayah di provinsi jawa timur selama masa Pandemi Covid 19.

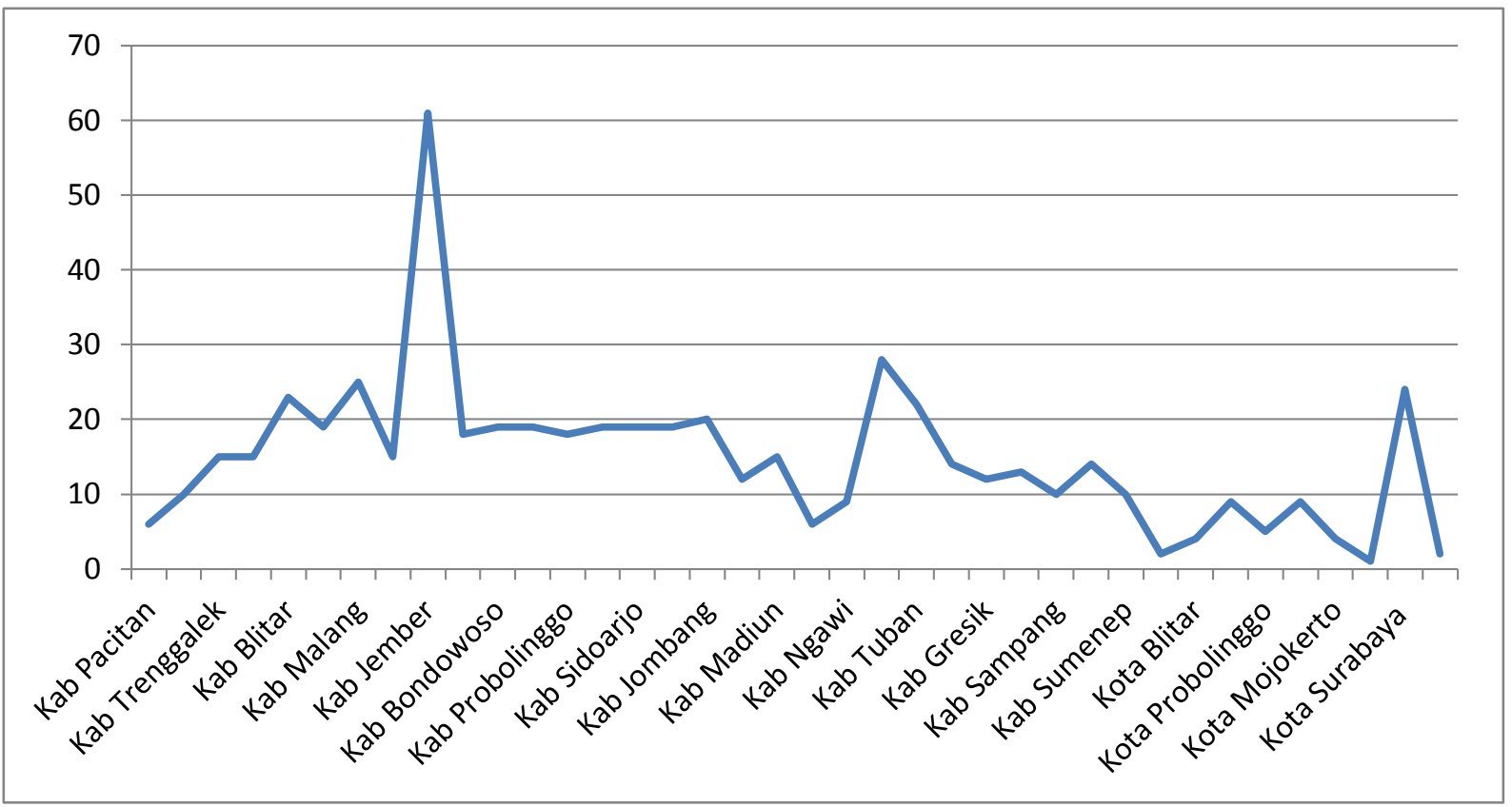

Dari Gambar 1 dapat disimpulkan bahwa selama pandemi, angka kematian ibu tertinggi di Provinsi Jawa Timur terjadi di Pasuruan 


\section{E. PEMBAHASAN}

Keterjangkauan lokasi pelayanan kesehatan, dimana letak pelayanan tidak strategis/sulit dijangkau oleh ibu, menyebabkan berkurangnya akses ibu hamil terhadap pelayanan kesehatan, jenis dan kualitas pelayanan yang tersedia serta keterjangkauan informasi. Akses ke fasilitas pelayanan kesehatan dapat dilihat dari beberapa faktor, seperti lokasi ibu dapat memperoleh pelayanan kontrasepsi, pemeriksaan kehamilan, pelayanan kesehatan dasar atau pelayanan kesehatan rujukan yang tersedia di masyarakat.

Pelayanan antenatal adalah pelayanan kesehatan yang dilakukan oleh tenaga kesehatan profesional (dokter kandungan dan dokter spesialis kandungan, dokter umum, bidan dan perawat) seperti pengukuran berat badan dan tekanan darah, pemeriksaan tinggi fundus uteri, imunisasi tetanus toxoid (TT) dan pemberian tablet besi pada ibu hamil selama masa kehamilan.

Masa kehamilan sesuai dengan pedoman antenatal care yang ada dengan menitikberatkan pada kegiatan promotif dan preventif. Hasil pelayanan antenatal dapat dilihat dari cakupan pelayanan K1 dan K4 (Kemenkes RI, 2013). Cakupan K1 atau disebut juga dengan akses pelayanan kesehatan bagi ibu hamil merupakan gambaran besar kecilnya ibu hamil yang pertama kali melakukan kunjungan ke fasilitas kesehatan untuk mendapatkan pelayanan antenatal. Sedangkan cakupan K4 merupakan gambaran besarnya ibu hamil yang mendapatkan pelayanan ibu hamil sesuai standar dan minimal 4 kali kunjungan dengan distribusi satu kali pada trimester pertama, satu kali pada trimester kedua dan dua kali pada trimester ketiga. Rendahnya cakupan K4 menunjukkan masih banyak ibu hamil yang tidak melanjutkan sampai kunjungan ke-4 pada trimester ke-3 sehingga kehamilannya lepas dari pengawasan petugas kesehatan. Kondisi ini dapat meningkatkan kemungkinan kematian ibu. Indikator kunjungan antenatal care (ANC) terdiri dari 4 jenis, antara lain: kunjungan antenatal semester pertama dan terakhir (K1 \& K4), cakupan imunisasi TT, dan cakupan pemberian tablet Fe. Salah satu standar minimal pelayanan antenatal adalah pemberian imunisasi TT. Tujuan pemberian imunisasi TT adalah untuk memberikan perlindungan pasif pada ibu hamil terhadap tetanus, vaksinasi ini juga membantu menghindari tetanus selama beberapa minggu pada bayinya yang baru lahir (Fauziah\&Sutejo, 2012).

Penelitian Oyerinde, Bauserman dkk bahwa kurangnya kunjungan antenatal care memiliki risiko kematian ibu 1,8 kali, ibu dengan kuantitas antenatal sedikit lebih rentan terhadap kematian sebesar 5.444 kali (Astuti SK, Aziz MA, Arya IFD, 2017; Oyerinde K, 2013). Sementara itu, Yego et al., pada ibu yang tidak melakukan kunjungan antenatal care memiliki risiko 4,1 kali kematian ibu (Yego F, et al, 2014). Penelitian Kumar dan Agrawal (2016) dalam penelitiannya "Brought in Dead: An Avoidable Delay in Maternal Deaths" menemukan bahwa keterlambatan staf penanganan menjadi penyebab kematian ibu sebesar 56,25\% (Kumar N, 2016). Pelayanan antenatal dilakukan agar dapat dilakukan pengawasan yang lebih intensif, pengobatan agar risiko dapat dikendalikan, dan dapat dilakukan rujukan tindakan yang memadai (Marabele, P. M et al, 2020; Menendez et al, 2020). Pelayanan yang dilakukan secara rutin juga merupakan upaya untuk melakukan deteksi dini kehamilan berisiko sehingga dapat segera dilakukan tindakan yang tepat untuk mengatasi dan merencanakan serta memperbaiki kehamilan tersebut. Kelengkapan antenatal terdiri dari jumlah kunjungan antenatal dan kualitas pelayanan antenatal. Asuhan antenatal memiliki pengaruh yang baik terhadap pertumbuhan janin atau lamanya kehamilan, 
baik dengan diagnosis maupun dengan pengobatan komplikasi kehamilan secara teratur (Nurrizka, R. H., 2018). Pertama kali seorang ibu hamil melakukan pemeriksaan kehamilan merupakan waktu yang sangat penting, karena berbagai faktor risiko dapat diidentifikasi sedini mungkin dan dapat segera dikurangi atau dihilangkan. Kebijakan teknis pelayanan antenatal setiap kehamilan dapat berkembang menjadi masalah atau komplikasi sewaktu-waktu. Karena itulah ibu hamil perlu pemantauan selama kehamilannya.

Penatalaksanaan ibu hamil secara keseluruhan meliputi komponen-komponen sebagai berikut: mengupayakan kehamilan yang sehat, melakukan penatalaksaan dini dan rujukan bila perlu, mempersiapkan persalinan yang bersih dan aman, perencanaan antisipatif dan persiapan dini rujukan jika terjadi komplikasi.

Kualitas pelayanan antenatal sangat erat kaitannya dengan pelaksanaan standar pelayanan kebidanan, dimana standar pelayanan bermanfaat dan penerapan norma serta tingkat kinerja yang diperlukan untuk mencapai hasil yang diinginkan18. Penerapan standar pelayanan sekaligus akan melindungi masyarakat, karena penilaian terhadap proses dan hasil penilaian dapat dilakukan secara jelas. Preeklamsia dan eklampsia merupakan komplikasi kehamilan yang sedang berlangsung, oleh karena itu melalui pemeriksaan kehamilan yang bertujuan untuk mencegah berkembangnya preeklampsia, atau paling tidak dapat dideteksi secara dini sehingga dapat menurunkan angka kejadian nyeri. Pada preeklamsia stadium awal, tidak ada gejala yang dapat dirasakan oleh pasien sendiri, sehingga diagnosis dini hanya dapat dilakukan dengan pemeriksaan antenatal care. Jika ibu hamil melakukan kunjungan mingguan ke klinik prenatal selama 4-6 minggu terakhir kehamilannya, ada kesempatan untuk melakukan tes proteinuria, mengukur tekanan darah dan memeriksa tanda-tanda edema.

Setelah mengetahui diagnosis dini, maka perlu segera dilakukan penanganan untuk mencegah masuknya eklampsia. Selain faktor-faktor yang telah diketahui, buruk atau tidaknya kondisinya juga ditentukan oleh baik tidaknya asuhan antenatal. Dari $70 \%$ pasien primigravida yang menderita preeklamsia, 90\% diantaranya tidak melakukan pemeriksaan kehamilan. Antenatal Care adalah cara untuk memantau dan mendukung kesehatan ibu hamil normal dan mendeteksi komplikasi. Pelayanan Antenatal Care penting dilakukan untuk memastikan proses alami kehamilan berjalan normal dan tetap demikian. Kehamilan dapat berkembang menjadi masalah atau komplikasi setiap saat.

Sekarang secara umum diterima bahwa setiap kehamilan membawa risiko bagi ibu. Kebijakan program dalam pelayanan. Antenatal Care yaitu kunjungan antenatal harus dilakukan minimal 4 kali selama kehamilan, satu kali pada trimester pertama, satu kali pada trimester kedua dan dua kali pada trimester ketiga.

Masa nifas adalah masa 6-8 minggu setelah melahirkan dimana organ reproduksi sedang dalam masa pemulihan untuk kembali normal. Namun secara umum, organ reproduksi akan kembali normal dalam waktu 3 bulan setelah melahirkan. Kunjungan nifas minimal 3 kali dengan distribusi waktu: 1). Kunjungan postpartum pertama pada 6 jam setelah melahirkan sampai dengan 3 hari; 2). Kunjungan nifas kedua dilakukan pada minggu ke-2 setelah melahirkan; 3). Kunjungan nifas ketiga dilakukan pada minggu ke-6 pasca persalinan. Diharapkan kunjungan nifas ini dilakukan bersamaan dengan kunjungan neonatus di posyandu.

Komplikasi yang timbul pada masa nifas dan nifas merupakan penyebab langsung kematian ibu. Komplikasi yang terjadi sebelum persalinan, selama dan setelah melahirkan terutama perdarahan, partus macet atau partus lama dan infeksi akibat 
trauma saat melahirkan.

Pada masa nifas, pelayanan kesehatan yang diterima oleh ibu nifas meliputi pemeriksaan keadaan umum (tekanan darah, nadi, pernafasan dan suhu), pemeriksaan lokia, dan keputihan lainnya, pemeriksaan payudara, dan penyuluhan pemberian ASI eksklusif selama 6 bulan, pemberian 200.000 kapsul vitamin A IU. 2 kali ( 2 x 24 jam) dan pelayanan KB pasca persalinan. Perawatan ibu nifas yang tepat akan mengurangi risiko kelainan atau bahkan kematian pada ibu nifas. Cakupan pelayanan nifas merupakan salah satu indikator kesehatan14. Meningkatnya cakupan pelayanan nifas menunjukkan bahwa tenaga kesehatan semakin proaktif dalam memberikan pelayanan kepada ibu nifas guna meminimalkan risiko kelainan bahkan kematian pada ibu nifas

\section{F. PENUTUP}

Dari GWR diketahui bahwa setiap wilayah di Provinsi Jawa Timur memiliki determinan yang spesifik terhadap angka kematian ibu pada masa pandemi, namun variabel pelayanan persalinan oleh tenaga kesehatan dan pelayanan antenatal berpengaruh signifikan terhadap angka kematian ibu

\section{G. DAFTAR PUSTAKA}

WHO. (2019). Maternal Mortality. Geneva:https://www.who.int/news-room/factsheets/detail/maternal-mortality

Corbett, G. A., Milne, S. J., Hehir, M. P., Lindow, S. W., O'connell, M. P. (2020). Health anxiety and behavioural changes of pregnant women during the COVID-19 pandemic. European journal of obstetrics, gynecology, and reproductive biology, 249, 96-97

Phoswa, W. N., Khaliq, O. P. (2020). Is pregnancy a risk factor of COVID19?. European Journal of Obstetrics and Gynecology and Reproductive Biology, 252, 605-609.

Lim, G., LaSorda, K. R., Farrell, L. M., McCarthy, A. M., Facco, F., Wasan, A. D. (2020). Obstetric pain correlates with postpartum depression symptoms: a pilot prospective observational study. BMC pregnancy and childbirth, 20, 1-14.

Arulita, I.F (2007). Risk factor that affected Maternal Mortality (Case study in Cilacap). Tesis. FKM-Universitas Diponegoro Semarang.

Astuti SK, Aziz MA, Arya IFD. (2017). Maternal Mortality Risk Factors in Dr. Hasan Sadikin General Hospital, Bandung in 2009-2013. International Journal of Integrated Health Sciences. 2017;5(2):52- 6

Oyerinde K. 2013. Can Antenatal Care Result in Significant Maternal Mortality Reduction in Developing Countries. J Community Med Health Educ. 2013;3(2)

Yego F, D’Este C, Byles J, Williams JS, Nyongesa P. (2014). Risk Factors for Maternal Mortality in a Tertiary Hospital in Kenya: a Case Control Study. BMC Pregnancy and Childbirth. 2014;14(38).

Ministry of Health RI. Basic Health Research. (2013). Jakarta: Health Research and Development Agency, Ministry of Health, Republic of Indonesia. 
Marabele, P. M., Maputle, M. S., Ramathuba, D. U., Netshikweta, L. (2020). Cultural factors contributing to maternal mortality rate in rural villages of Limpopo Province, South Africa. International Journal of Women's Health, 12, 691.

Mei, C. (2005). Geographically Weighted Regression Technique for Spatial Data Analysis. Theses. School of Science Xi'an Jiatong University.

Menéndez, C., Quintó, L., Castillo, P., Fernandes, F., Carrilho, C., Ismail, M. R., ... Moraleda, C. (2020). Quality of care and maternal mortality in a tertiary-level hospital in Mozambique: a retrospective study of clinicopathological discrepancies. The Lancet Global Health, 8(7), e965-e972.

McCarthy J and Maine D. (1992). A Framework for Analyzing the Determinants of Maternal Mortality. Pubmed diunduh di http://www.ncbi.nlm.nih.gov/pubmed/1557792 at 10 Februari 2020

Nurjannah, N., Maria, I., E, Rildayani, Sari, E. (2018). Spatial Analysis of Maternal Mortality Rate (MMR) with Midwife Ratio, and Delivery Coverage by Health Workers in Aceh Province 2017. Jurnal Kedokteran Nangroe Medika Vol 1 No 3, pp. 7-14.

Nurrizka, R. H., Wahyono, T. Y. M. (2018). Maternal Mortality Disparities in Indonesia: Ecological Studies with Spatial Analysis. Indonesian Public Health Media Hasanuddin University, 14(2), 119-127

Razzak, H., Ali, M., Ali, M. (2015). Principal Component Analysis of Socioeconomic Factors and Their Association With Life Expectancy At Birth In Asia. International Journal of Multidisciplinary Academic Research Vol.3 No.1, ISSN 2309-3218.

Kumar N. (2016). Postpartum Hemorrhage; a Major Killer of Woman: Review of Current Scenario. Obstet Gynecol Int J. 2016;4(4): 00116

Regression For Predicting The Number of Visits to Health Services Places Given Predictors Concerning Health Services System. An Evaluation Study of Social Security Net-Health Sector in East Java Provoince, Indonesia. Collection of Presented Papers at International Conference in Mathematics and Applications Mahidol University. Bangkok. Thailand.

Kuntoro. (2002). Introduction to Multivariate Statistics. Surabaya: Pustaka Melati.

Kuntoro. (2009). Philosophical Basis of Research Methodology. Surabaya: Pustaka Melati.

Fauziah and Sutejo. (2012). Pregnancy Maternity Nursing. Jakarta: Kencana Prenada Media Group 